\title{
Constructability and safety performance based design: a design and assessment tool for the building process.
}

\author{
P. Capone ${ }^{a}$, V. Getuli ${ }^{a}$ and T. Giusti ${ }^{a}$ \\ ${ }^{a}$ Università degli Studi di Firenze - DICEA, via di Santa Marta, 3- Firenze \\ E-mail: pcapone@dicea.unifi.it, vito.getuli@dicea.unifi.it,tommasog@dicea.unifi.it
}

\begin{abstract}
-
The theme of this contribution fits astride two strands of Construction Management Studies: "health and safety risk management" on construction site and "constructability" design approach. Specifically we faces two problems usually considered separately: the lack of specificity, synergy, effectiveness between safety planning and construction process and the lack of concurrence between design and construction process. The proposed approach assigns to design the key role of optimizing both constructability and safety planning in a unique and simultaneous procedure. The purpose is to improve "working plan" design level by specific construction simulation and the related safety assessment in the perspective of the better constructability performance and final building results. The proposed method is a Construction Management Approach supported by design tool based on working directly on design drawings. Starting from the representation of construction details, their construction can be simulated. This is obtained analyzing construction details by means of progressive drawings that express and simulate the breakdown of construction phases, chronologically processed and logically related. In these specific drawings all the elements of the construction site are graphically placed. The procedure allows both to perform the specific and detailed safety assessment for the realization of construction detail components, and to verify the constructability of them. The safety and constructability analysis is so performed in a graphical way during the design process not waiting the construction phase. So we are still able to intervene, if necessary, with amendments under the designer control.
\end{abstract}

Keywords -

Construction Management; Project Management; Safety; Constructability; Buildability; Design.

\section{Introduction}

In order to optimize the construction process and to achieve the best results, two strands of Construction Management studies should be investigated: "health and safety risk management" on construction site and "constructability" design approach.

The issue of safety on construction sites was born with the construction activity: the use of dangerous materials, the use of equipment and machineries in precarious and provisional environments and, above all, the need to "work at height", make the construction activity with a greater risk of accidents.

At the same time was born the need to direct and coordinate safety factors with all the other resources throughout the project instruments by using modern management techniques to achieve the objectives $[1,2]$.

The issue should be of interest for all researchers involved in Construction Management. It is wrong who still thinks it is a matter of tedious formalities, probably unnecessary.

In order to achieve the integration of "constructability" and "safety", investigation on working knowledge of general management and familiarity with the special knowledge domain related to the project are indispensable (Figure 1), [3].

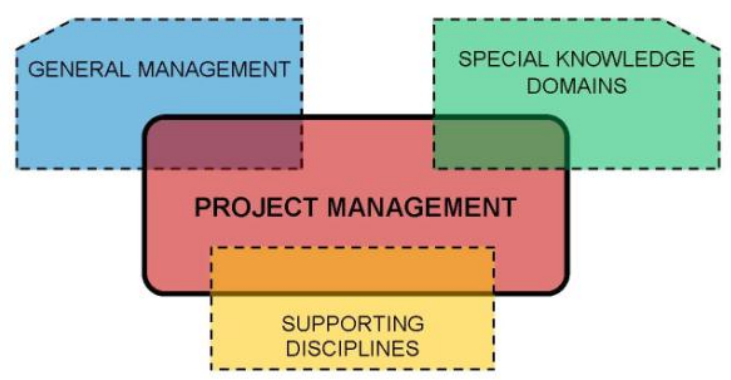

Figure 1. Basic Ingredients in Project Management (PMBOK Guide) 
Supporting disciplines such as computer science, decision support systems and drawing techniques, may also play an important role [4].

This paper faces two different kinds of problem, usually considered separately:

- the lack of specificity, synergy, effectiveness between safety planning and construction process;

- the lack of concurrence between design phase and construction process (Figure 2).

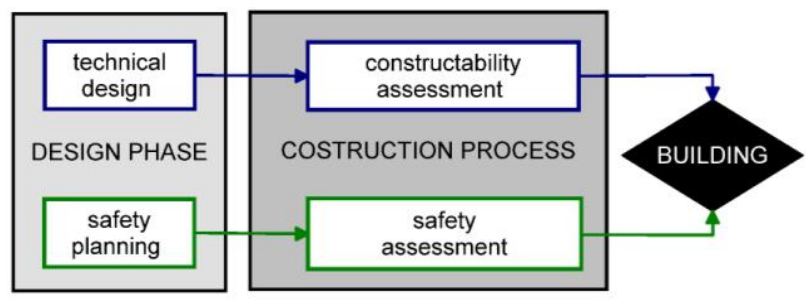

Figure 2. Schematization of the relationship between design phase and construction process

In order to take under control constructability and safety during design phase and not only during construction process, the proposed approach assigns to design the key role of optimizing both constructability studies and safety planning in a unique and simultaneous procedure.

This approach fits within the relationship "construction phase" - "design phase" (Figure 3).

The purpose is to improve "working plan" design level by specific construction simulation and the related safety assessment in the perspective of the better constructability performance and final building results.

The simulation is possible during design phase, that is the moment of building and construction site foreshadowing, together with all their related aspects.

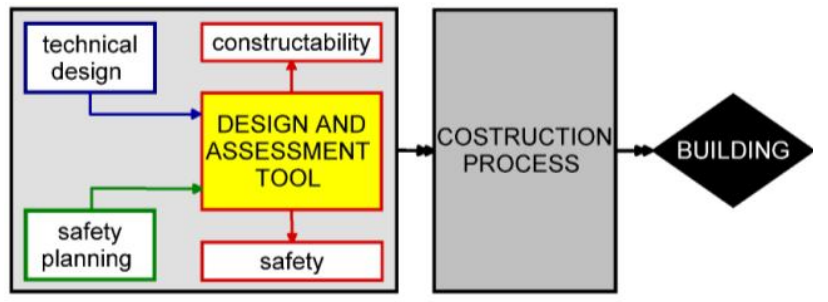

Figure 3. Schematization of the proposed relationship between design phase and construction process
Such issue comes from many Construction Management studies that deal with, in particular, the Constructability and Buildability theoretical field $[5,6,19]$.

Computation and scheduling of the intervention can change and the designer may lose the unified management of the process, losing this way the synthesis between intentions and proposal. The gap may be apparent and limited to the operational dynamics while preserving the essence of the unity between design intent and result of the construction [7].

Conversely, the project may be, in part or in full, of hard construction: the dynamics cannot be congruent with the intentions. The final result may be not consistent with the requirements and it will therefore be not acceptable in terms of quality [8].

Some important studies have been developed with the aim to manage constructability and safety by means of design $[14,15,16]$, other studies involved BIM to facilitate a smarter and safer infrastructure and building construction [17].

The proposed method (simulating dimensional, technical and technological characteristics of the building and construction site) tries to overcome the questions above specified.

\section{Suggestion for an effective design method}

This contribution concerns the Constructability, which embraces the functions both of project management and of design, covering a wider scope than the Buildability.

Constructability interacts with the project management techniques that utilize optimally knowledge and experiences on building effective, to improve the achievement of the project objectives. Constructability involves the entire design process $[9,18]$.

In these theories plays key role the project intended as a platform to maximize the interests of its most effective function, within the Construction Process in general and within the Building Construction in specific.

Talking about "optimization" is always dangerous, because the parameters should be defined and references needed to assess the actual improvement of this instrument.

The design influences construction cost, for example, because any decision made at the initial stage of a project life cycle has far greater influence than those made in later stages or during construction phase (Figure 4), [10]. 


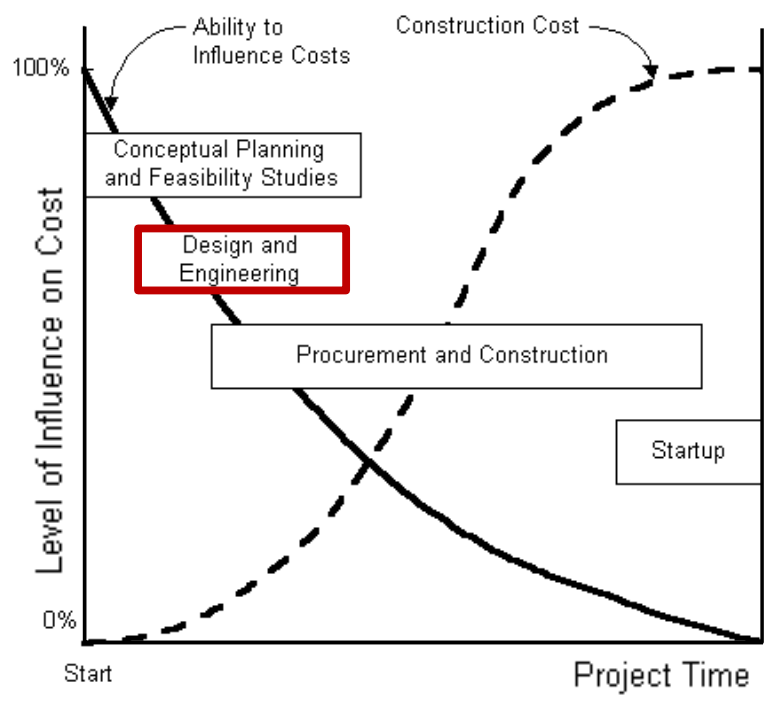

Figure 4. Ability to influence Construction Cost Over Time (Hendrickson \& Au)

Starting from the aforesaid studies, the method put the optimization of building process into the hands of construction simulation, later described, and design drawings.

In this perspective the safest route is to direct experimentation on the actual impact in terms of improving the "easy to build".

The basic question remains: "Which are the design elements that we can manage in order to improve their effectiveness in the construction site?".

In first instance, the answer is obviously twofold: the design contents and representation techniques. These two means are of course intimately related: the representation is nothing more than the explicit and objective view of the contents, which, in their textual expression, may be not clear.

In fact the representation is much more, as it allows you to contextualize the content, especially in terms of requirements and performance. The representation allows you to make content consistent, in a geometric and technological upgrading, with the specific artifact to be built and with the specific environment in which the construction will be inserted [11].

This consideration of "visualization and consistency", has provided the basic idea of the method we propose. The idea is that the graphical representation is not only "passive image" of the content, but it is the "active checks" in terms of specificity and consistency. So, why not trying to improve the content by performing the opposite: can an analysis of the representation define new contents? And more, why not accentuate the "dynamism" of the project whose representation usually goes for "static sections" of the final result?

Constructability and safety can be joined by design: this is the reason why it is interesting to work directly on design drawings. The proposed method can be defined as a Construction Management approach supported by a design tool directly based on design drawings [12].

\section{The method}

The core of this approach is to intervene on the working drawings to simulate the construction process, usually only implicit in the representation of the "result". As preliminary phase it is necessary to define the construction site global needing: boundary conditions, site peculiarities, external constrains. This is useful in order to be able to manage every single element that can participate or even interfere with the construction phase.

After this, the method can be performed: it consists in the application of the methodological procedure described in par. 3.1 by means of the design tool described in par. 3.2 .

\subsection{Methodological procedure}

The classic representation of the "finished product" holds a critical background: completeness graphics imposes a "designed order" often associated with a construction sequence whose effectiveness has yet to be demonstrated. Even if the performance takes place in a conscious way, with attention to the technological stratification in terms of the logic of performance, it may happen that it has not "constructive effectiveness". The graphical representation may have no correspondence with the needs the construction site and the specific production process.

The methodological procedure involves a preliminary choice of construction details of the building. These technological details must be meaningful to their difficulty of execution or their repetition within the building structure.

Every selected detail expected in the final design is examined and its "constructability analysis" is processed, according to the logic diagram shown in Figure 5.

Starting from the representation of selected constructive details, their construction can be simulated. This is obtained analyzing them by means of progressive drawings that express and simulate the breakdown of construction phases, chronologically processed and logically related (Figure 6). 


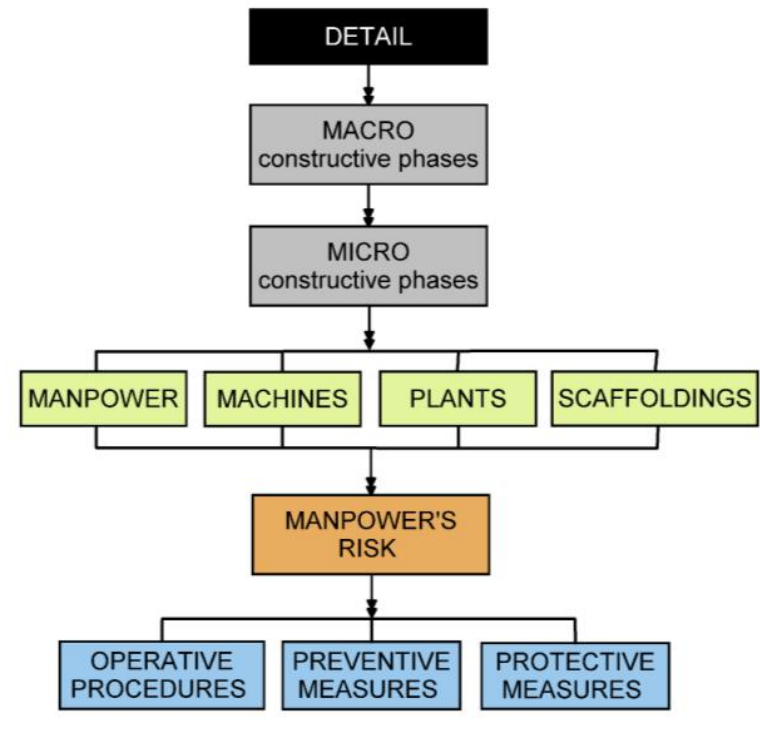

Figure 5. Diagram showing the methodological procedure

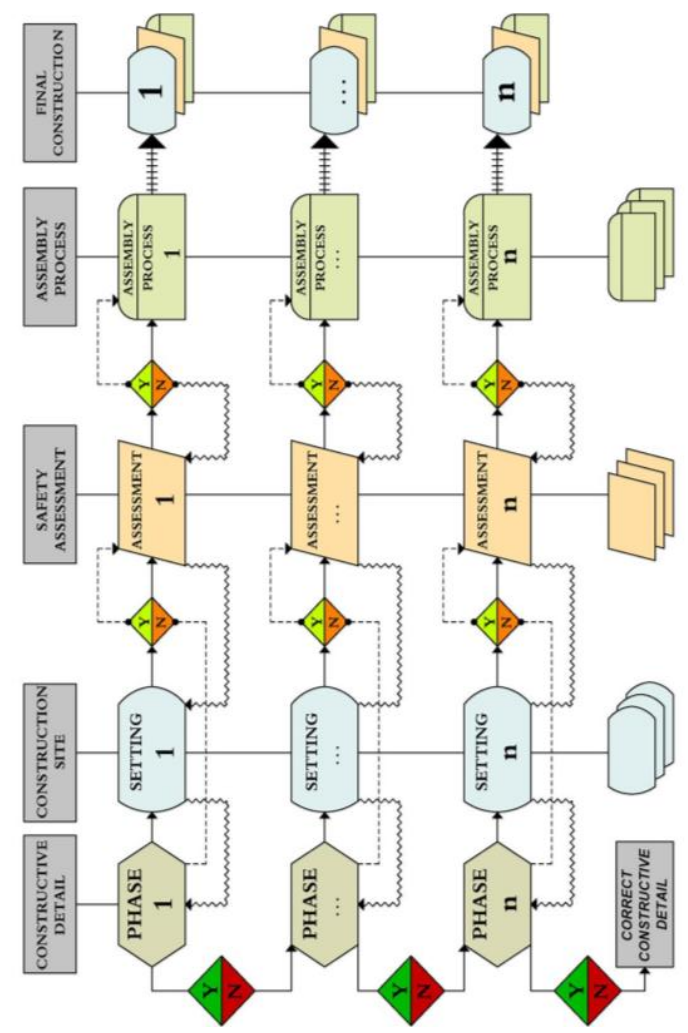

Figure 6. Operative flow chart of the procedure

In these specific drawings, which are in the same number of phases, all the elements of the construction site are graphically placed (scaffoldings, machinery, manpower, etc.).

The procedure allows both to perform the specific and detailed safety assessment for the realization of the construction details, and to verify the constructability of them.

Figure 7 shows the application of the operative flowchart to a simple case study.

\subsection{Operative framework}

Methodological procedure is performed by means of an encoded design tool described in the follow.

In terms of graphic representation, in view of a likely professional application, an A3 sheet size (according to ISO 216) is used in pursuit of greater manageability in construction site.

The table is divided into three main areas (Figure 8), with a strict logical and sequential concatenation according to the scheme earlier shown in Figure 6, but with a free graphic expression.

\section{Graphic representation of the construction detail and the specific phase of work to accomplish.}

It must be the predominant element in the table. In terms of communication, what you are referring to it has to be immediately understood. Compared to a traditional graphical representation, it has to provide a large range of information relating to construction needs. To this purpose, it may be useful to integrate the planimetric detail with diagrams and section to clearly contextualize it within the building, or possibly with images - in case you are in the presence of a required conversion of an existing building.

It has to be represented:

- the position of operators: workers can be summarized with symbols in the form of a dimensionless logo to simplify the engagement representative;

- the presence of machinery: machines can be summarized, as workers, with symbols in the form of dimensionless logo;

- the presence of temporary structures: it's important to have scale draw of the temporary structures because of their physical interaction and interference with the building structure under construction.

The following color code is used (Figure 8):

- Black for the parts of the building already constructed;

- Red for the analyzed construction phase;

- Blue for temporary works necessary to the workers to reach the correct workplace;

- Green for the temporary works of structural support.

The dynamic variation of colors from a table to another expresses the evolution of the construction. 
2. Description of the analyzed working phase with the specific type of manpower, equipment and machinery needed.

This part, complementary to the first one, integrates and explicates all the construction information of the analyzed working phase (Figure 8).

3. Risk assessment and identification of individual and collective measures to prevent and protect.

This section provides an analysis of the data

\section{PHASE n.1}

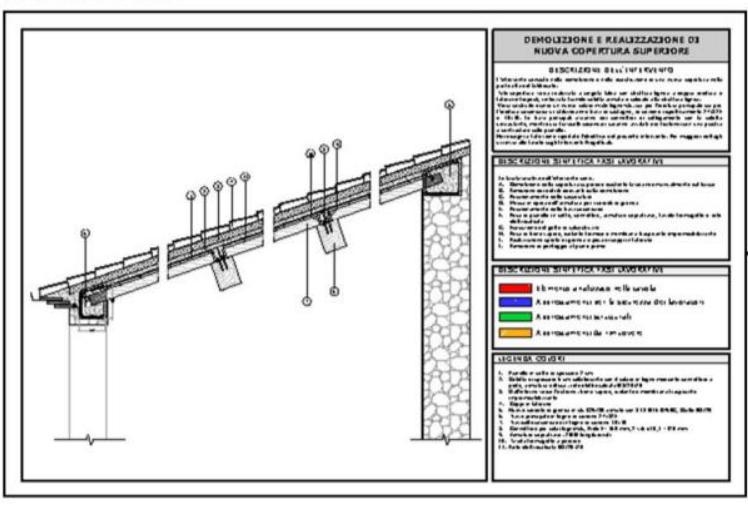

PHASE n.4
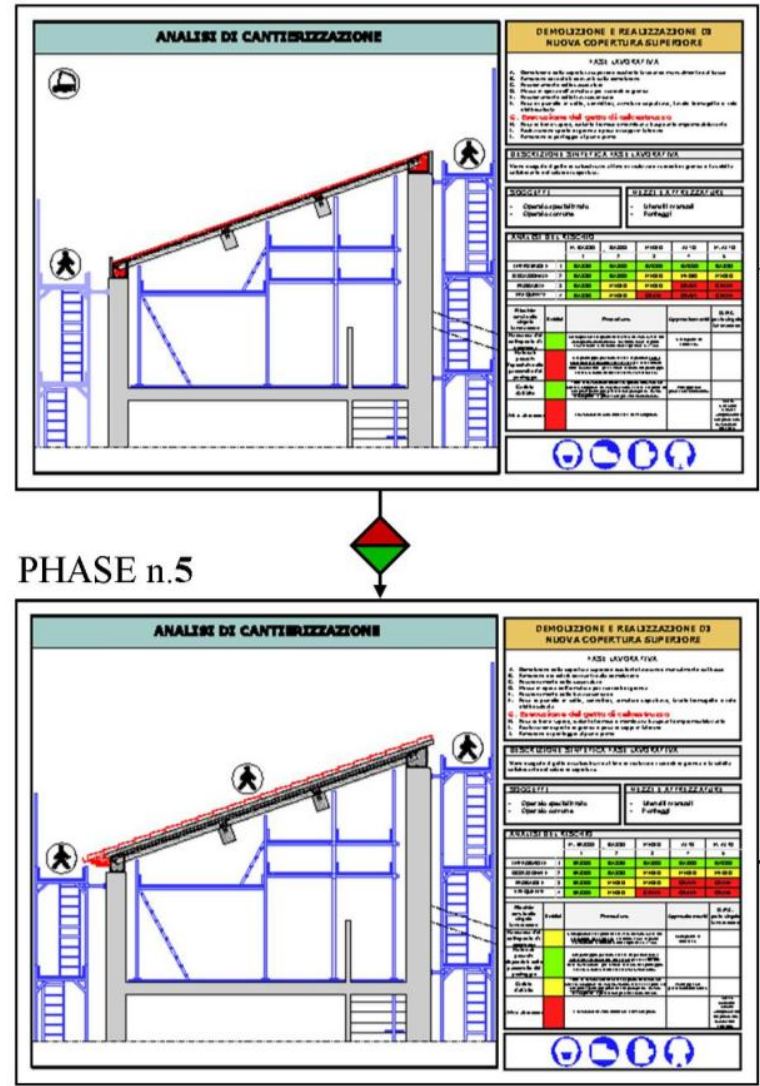

explained by the graphical representation. We highlight the critical issues that come from the constructive simulation of the specific phase, both in terms of building site settlement and in terms of worker safety. This section also explicit critical issues due to the interaction "man-machine", "manprovisional structure", "man-structure" (Figure 8).

PHASE n.2
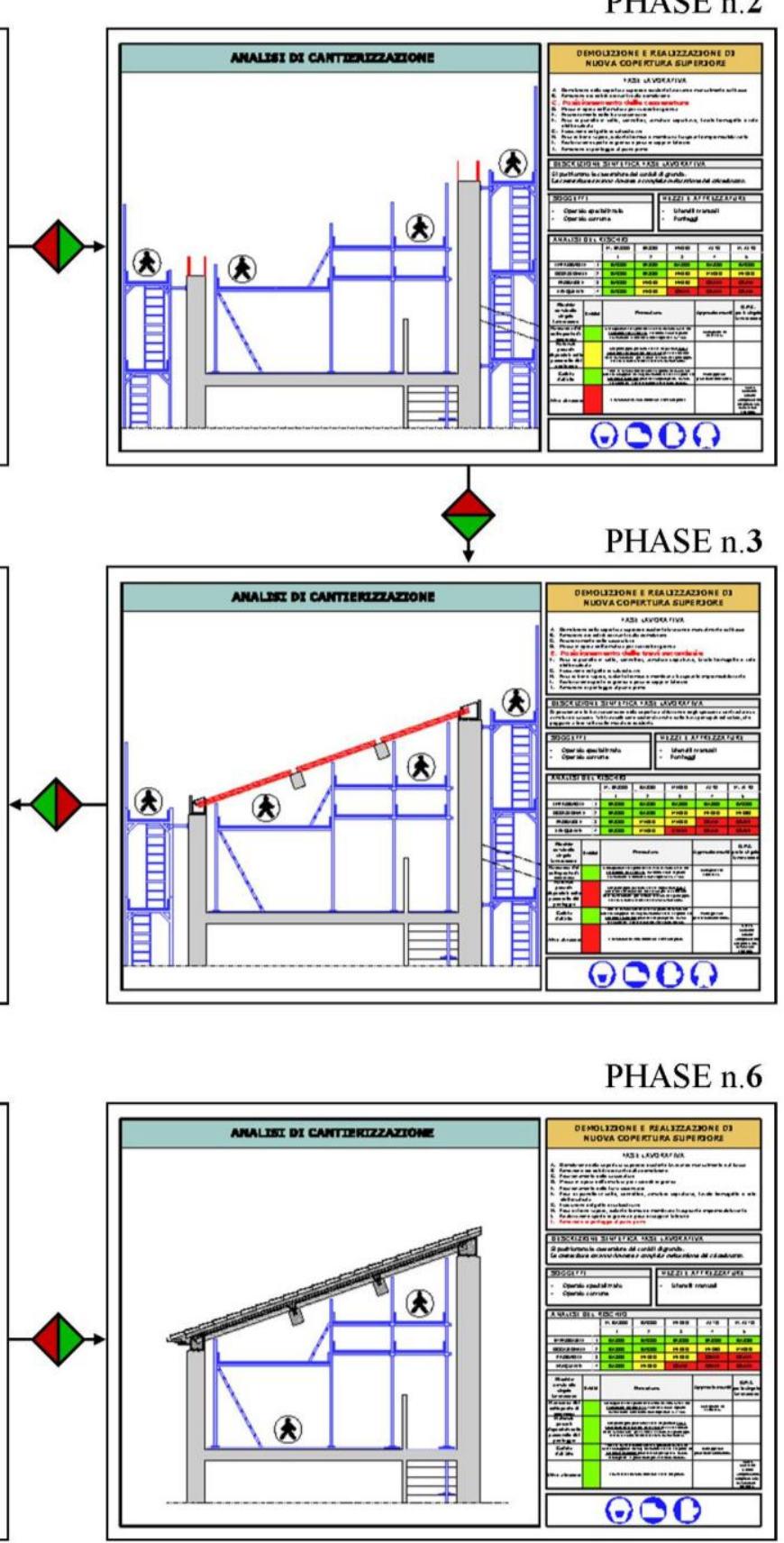

Figure 7. Tables drawn according to the Operative Framework and connected as in Operative Flow Chart in figure 6 - Example of roof redevelopment 


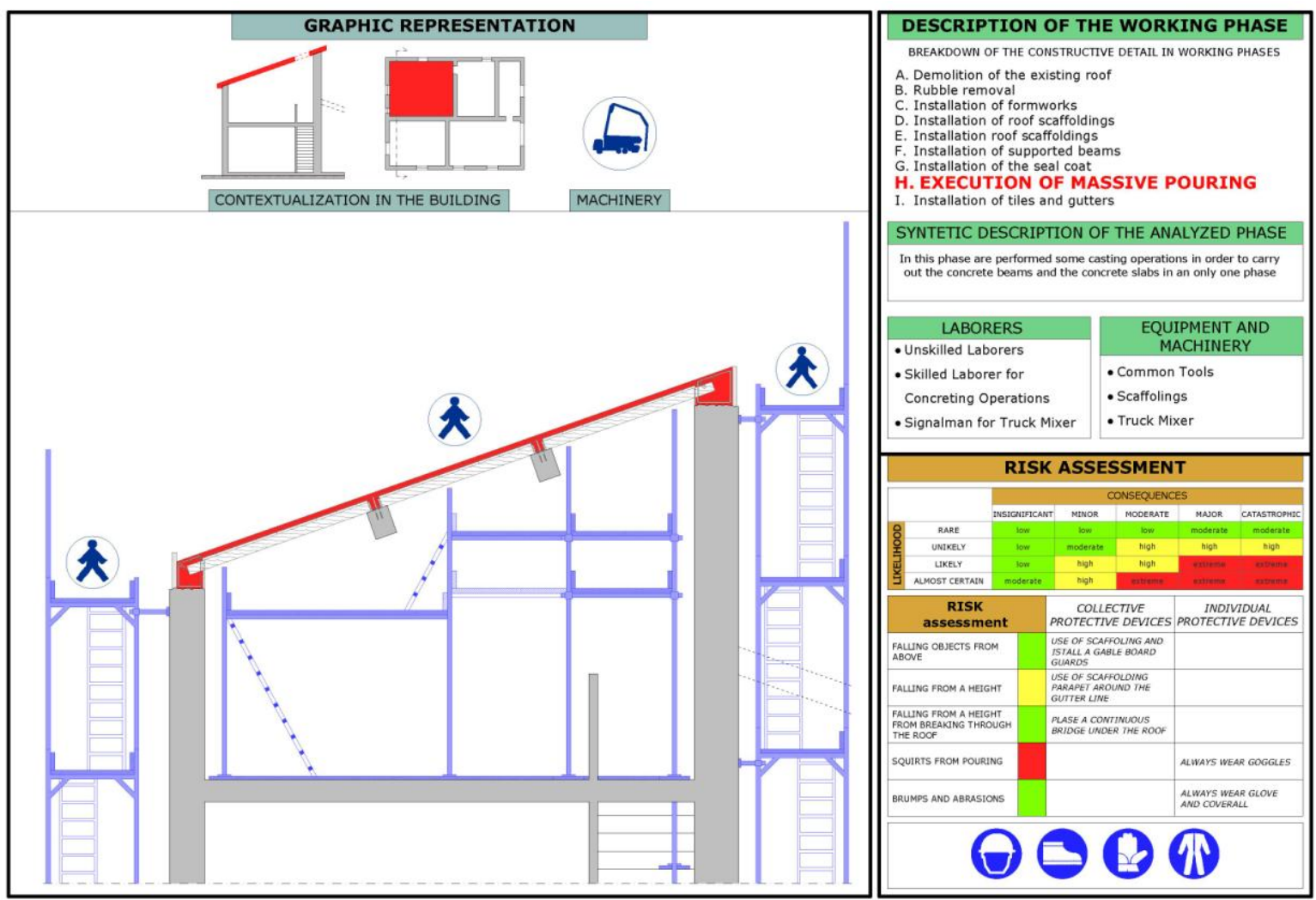

Figure 8. An example of the graphic composition of the table according to the proposed method

\subsection{First applications and results}

During last years, we have applied the proposed design and assessment tool for the building process in a wide range of situation (Figure 9). The followed criteria in choosing the case studies were mainly regarding:

\section{- Typology of building intervention.}

The tool can be adapted for each typology of intervention, starting from the maintenance till coming to the new construction, passing through the building redevelopment.

- Structural system typology.

We have some invariant steps according the specific structural technology (i.e. concrete frame buildings, wooden structures, steel structures).

\section{- Typology of Graphical representation.}

It is necessary to choose the more appropriate way to represent with effectiveness the building we deal with. We performed $2 \mathrm{D}$ and $3 \mathrm{D}$, in order to make the representation the most communicative we could.

- Type of workers.

We tried to modify the tool's language adapting it to the final users, which are nothing else that workers. Multilingual versions of the tables were produced, as well as representations dedicated to self-builders.

By the linear combination of the above set of criteria, hundreds of tables were produced on the base of real case studies. Some of the produced tables directly influenced the construction process, as well as they suggested different technological solutions to the designer, with the aim to make the building consistent with the design idea.

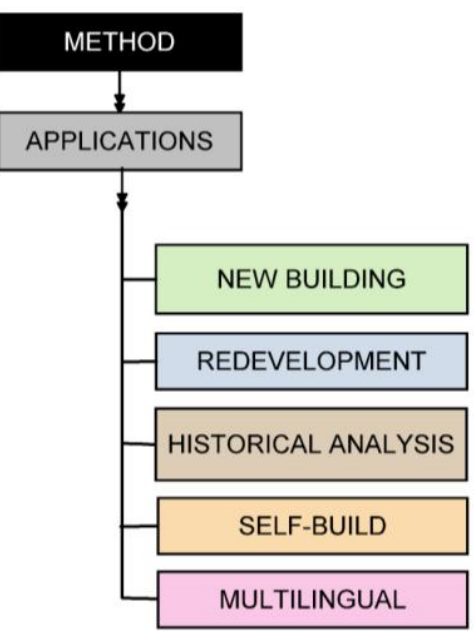

Figure 9. Diagram showing the possible applications 


\section{Conclusion \& Discussion}

At first, an attempt was made to assimilate this process in some of the planning security tools provided by European and Italian law. The instrument that seems more adaptable is Safety and Coordination Plan (PSC, as defined in Italian law). In experimental applications performed in the last few years, we have used the definition of "Graphic PSC". We realized however, that this definition was too restrictive: the proposed method it is not only a graphic representation but is based on a theoretical approach that leads to a constructability and safety performance based design.

The final product of our design procedure is an assessment tool for the building process.

The method allows both to perform the specific and detailed safety assessment for the realization of construction detail components, and to verify the constructability of them.

The safety and constructability analysis is firmly performed in an encoded graphical way during the design process, not waiting the construction phase. So we are still able to intervene, if necessary, with amendments under the designer control.

At the moment we are working to implement the tool in a software application. If we apply the proposed design to a wide database, by the help of a BIM software [13], we will be able to automate the procedure to perform the constructability and safety performance based design exactly during the design phase.

\section{References}

[1] See R. M. Wideman, The PMBOK Report - PMI Body of Knowledge Standard, Project Management Journal, Vol. 17, No. 3, August 1986, pp. 15-24

[2] Barrie, Donald S. and Body C. Paulson, Professional Construction Management, McGraw-Hill Book Company, $2^{\text {nd }}$ Ed., 1984

[3] See L. C. Stuckenbruck, Project Management Framework, Project Management Journal, Vol. 17, No.3, August 1986, pp. 25-30

[4] Project Management Institute, A Guide to the Project Management Body of Knowledge, Newtown Square, Pennsylvania, 2000

[5] Ferguson I., Buildability in Practise, Mitchell Publishing Co., London, 1989

[6] Construction Industry Institute Australia (CII
Australia), Constructability Manual, CII Aurstralia, Australia, 1996

[7] Francis, Mehrtens, Sidwell and McGeorge, Constructability Strategy for Improved Project Performance, Architectural Science Review, 1999

[8] Jergeas G. and Put J.V.D., Benefits of Constructability on Construction Project, Journal of Construction Engineering and Management, pp. 281-290

[9] Griffith A. and Sidwell A.C., Constructability in Building and Engineering Projects, Macmillan Press Ltd, Basingstoke, 1995

[10] Hendrickson, C., \& Au, T., Project Management for Construction, Pittsburg, 1989

[11] Pulaski M. H., Horman M. J., Organizing Constructability knowledge for Design, Journal of Construction Engineering and Management, 2005, pp. 911-919

[12] Capone P., Constructability and Safety Assessment Design Approach, in: IN_BO. Ricerche e progetti per il territorio la città e l'architettura, Bologna, 2013

[13] $\mathrm{Hu} \mathrm{Z,} \mathrm{Zhang} \mathrm{J,} \mathrm{Deng} \mathrm{Z,} \mathrm{Construction} \mathrm{process}$ simulation and safety analysis based on building information model and 4D technology, Tsinghua Science \& Technology, Elsevier, 2008, pp. 266-272

[14] Hijazi W., Alkass S., Zayed T., Constructability Assessment Using BIM/4D CAD Simulation Model, AACE International Transactions, 2009

[15] Toole T. M., Gambatese J., The Trajectories of Prevention through Design in Construction , Journal of Safety Research 39, 2008, pp. 225-230

[16] Weinstein M., Gambatese J., Hecker S., Can Design Improve Construction Safety?: Assessing the Impact of a Collaborative Safety-in-Design Process, Journal of Construction Engineering and Management, Vol. 131, No. 10, 2005

[17] Chi S., Hampson K., Biggs H., Using BIM for Smarter and Safer Scaffolding and Formwork Construction: A Preliminary Methodology, Modelling and Building Health and Safety,, Singapore, 2012 
[18] Lam P. T. I., Wong F. W. H., Chan A. P. C., Contributions of designers to improving buildability and constructability, Design Studies Volume 27, Issue 4, July 2006, Pages 457-479

[19] Wong F. W. H., Lam P. T. I., Chan A. P. C., Shen, L. Y., A study of measures to improve constructability, International Journal of Quality \& Reliability Management Vol. 24 No. 6, 2007 pp. 586-601 